DOI: $10.17516 / 1997-1397-2021-14-2-150-158$

УДК 517.9

\title{
Fixed Points of Set-valued F-contraction Operators in Quasi-ordered Metric Spaces with an Application to Integral Equations
}

\author{
Ehsan Lotfali Ghasab* \\ Hamid Majani ${ }^{\dagger}$ \\ Department of Mathematics \\ Shahid Chamran University of Ahvaz \\ Ahvaz, Iran \\ Ghasem Soleimani Rad ${ }^{\ddagger}$ \\ Young Researchers and Elite club, West Tehran Branch \\ Islamic Azad University \\ Tehran, Iran
}

Received 01.01.2020, received in revised form 22.09.2020, accepted 20.11.2020

Abstract. In this paper, we prove some new fixed point theorems involving set-valued $F$-contractions in the setting of quasi-ordered metric spaces. Our results are significant since we present Banach contraction principle in a different manner from that which is known in the present literature. Some examples and an application to existence of solution of Volterra-type integral equation are given to support the obtained results.

Keywords: fixed point, sequentially complete metric spaces, $F$-contraction, ordered-close operator.

Citation: E.L.Ghasab, H. Majani, G.S.Rad, Fixed Points of Set-valued F-contraction Operators in Quasi-ordered Metric Spaces with an Application to Integral Equations, J. Sib. Fed. Univ. Math. Phys., 2021, 14(2), 150-158. DOI: 10.17516/1997-1397-2021-14-2-150-158.

\section{Introduction and preliminaries}

It is well known that the Banach contraction principle is a very useful and classical tool in nonlinear analysis [3]. After that, the generalization of this principle has been a heavily investigated. For example, in 1969, Nadler [10] extended the Banach contraction principle for set-valued mapping as follows:

Theorem 1.1. Let $(X, d)$ be a complete metric space and $T: X \rightarrow C B(X)$ be a set-valued operator. Also, let $H: N(X)^{2} \rightarrow[0,+\infty]$ be the Hausdorff metric on $N(X)$ which defined by

$$
H(A, B)=\max \left\{\sup _{a \in A} D(a, B), \sup _{b \in B} D(b, A)\right\},
$$

where $D(a, B)=D(B, a)=\inf _{b \in B} d(a, b)$. Assume that there exists $\alpha \in[0,1)$ such that $H(T x, T y) \leqslant \alpha d(x, y)$ for all $x, y \in X$. Then $T$ has a fixed point in $X$.

*e-lotfali@stu.scu.ac.ir https://orcid.org/0000-0002-8418-9351

†Correspondent: h.majani@scu.ac.ir; majani.hamid@gmail.com

$\ddagger$ gha.soleimani.sci@iauctb.ac.ir; gh.soleimani2008@gmail.com

https://orcid.org/0000-0001-7022-6513

C) Siberian Federal University. All rights reserved

https://orcid.org/0000-0002-0758-2758 
Then Cirić [6] extended Nadler's result as follows:

Theorem 1.2. Let $(X, d)$ be a complete metric space and $T: X \rightarrow C B(X)$ be a set-valued operator. Assume that there exists $\alpha \in[0,1)$ such that $H(T x, T y) \leqslant \alpha M(x, y)$ for all $x, y \in X$, where

$$
M(x, y)=\max \left\{d(x, y), D(x, T x), D(y, T y), \frac{1}{2}[D(x, T y)+D(y, T x)]\right\} .
$$

Then $T$ has a fixed point in $X$.

In 2011, Amini-Harandi [2] considered some fixed point theorem for set-valued quasicontraction mappings in metric spaces.

Theorem $1.3([2])$. Let $(X, d)$ be a complete metric space and $T: X \rightarrow C B(X)$ be a $k$-set-valued quasi-contraction with $k \in\left[0, \frac{1}{2}\right)$; that is,

$$
H(T x, T y) \leqslant k \max \{d(x, y), D(x, T x), D(y, T y), D(x, T y), D(y, T x)\}
$$

for all $x, y \in X$. Then $T$ has a fixed point in $X$.

On the other hands, Ran and Reurings [12], and Nieto and Rodríguez-López [11] studied the Banach contraction principle distinctly from another point of view. They imposed a partial order to the metric space $(X, d)$ and discussed on the existence and uniqueness of fixed points for contractive conditions and for the comparable elements of $X$ (also, see $[1,4,6-8,13,15]$ ). Moreover, in 2012, Wardowski [14] obtained a new fixed point theorem concerning $F$-contraction for single-valued mapping.

Theorem 1.4 ([14]). Let $(X, d)$ be a complete metric space and $T: X \rightarrow X$ be an F-contraction. Then $T$ has an unique fixed point $x^{*} \in X$ and for every $x_{0} \in X$ a sequence $\left\{T^{n} x_{0}\right\}_{n \in \mathbb{N}}$ is convergent to $x^{*}$.

In this paper, we obtain several fixed point results for set-valued $F$-contraction mappings in quasi-ordered metric spaces. Also, we prepare some examples and an application to the existence of a solution for Volterra-type integral equation. Throughout this paper, the family of all nonempty closed and bounded subsets of $X$ is denoted by $C B(X)$, and the family of all nonempty subsets of $X$ by $N(X)$.

Definition $1.1([9])$. Let $(X, d)$ be a metric space with a quasi-order " $\preceq$ " (pre-order or pseudoorder; that is, a reflexive and transitive relation). We say that $X$ is sequentially complete if every Cauchy sequence whose consecutive terms are comparable in $X$ converges.

Definition $1.2([9])$. Let $(X, d)$ be a metric space with a quasi-order " $\preceq$ ". For two subsets $A$, $B$ of $X$, we say that $A \sqsubseteq B$ if each $a \in A$ and each $b \in B$ imply that $a \preceq b$.

Definition $1.3([9])$. Let $(X, d)$ be a metric space with a quasi-order " $\preceq$ ".

(i) A subset $D \subset X$ is said to be approximative, if the set-valued mapping $P_{D}(x)=\{p \in D$ : $d(x, D)=d(p, x)\}$ for all $x \in X$ has nonempty value.

(ii) The set-valued mapping $G: X \longrightarrow N(X)$ is said to be have approximative values (for short, $\mathrm{AV})$, if $G x$ is approximative for each $x \in X$.

(iii) The set-valued mapping $G: X \longrightarrow N(X)$ is said to be have comparable approximative values (for short, $\mathrm{CAV}$ ), if $G x$ has approximative values for each $x \in X$ and for each $z \in X$, there exists $y \in P_{G z}(x)$ such that $y$ is comparable to $z$. 
(iv) The set-valued mapping $G: X \longrightarrow N(X)$ is said to be have upper comparable approximative values (for short, UCAV), if $G x$ has approximative values and for each $z \in X$, there exists $y \in P_{G z}(x)$ such that $y \succeq z$.

(v) The set-valued mapping $G: X \longrightarrow N(X)$ is said to be have lower comparable approximative values (for short, LCAV), if $G x$ has approximative values and for each $z \in X$, there exists $y \in P_{G z}(x)$ such that $y \preceq z$.

Definition $1.4([9])$. The set-valued mapping $G$ is said to has a fixed point if there exists $x \in X$ such that $x \in G x$.

\section{Main result}

From the idea of Wardowski [14], we consider a new type of $F$-contraction for set-valued operator in quasi-ordered metric spaces as follows.

Definition 2.1. Let $H: N(X)^{2} \rightarrow[0,+\infty]$ be the Hausdorff metric on $N(X)$ and $F: \mathbb{R}^{+} \longrightarrow \mathbb{R}$ be a mapping satisfying the following conditions:

(F1) $F$ is increasing, i.e., for all $a, b \in \mathbb{R}^{+}$such that $a \leqslant b$, then $F(a) \leqslant F(b)$;

(F2) for each sequence $\left\{a_{n}\right\}_{n \in \mathbb{N}}$ of positive numbers $\lim _{n \rightarrow \infty} a_{n}=0$ if and only if $\lim _{n \rightarrow \infty} F\left(a_{n}\right)=-\infty$;

(F3) there exists $k \in(0,1)$ such that $\lim _{\alpha \rightarrow 0^{+}} \alpha^{k} F(\alpha)=0$.

A mapping $G: X \longrightarrow C B(X)$ is said to be an $F$-contraction if there exists $\tau>0$ such that

$$
H(G x, G y)>0 \Longrightarrow \tau+F(H(G x, G y)) \leqslant F(d(x, y))
$$

for all $x, y \in X$.

Example 2.1. If $F(a)=\ln a+a$ for all $a>0$ and $H: N(X)^{2} \rightarrow[0,+\infty]$ is the Hausdorff metric on $N(X)$, then $F$ satisfies (F1)-(F3) and each mapping $G: X \longrightarrow C B(X)$ is an $F$-contraction such that $H(G x, G y) e^{H(G x, G y)-d(x, y)} \leqslant e^{-\tau} d(x, y)$ for all $x, y \in X$.

Example 2.2. If $F(a)=\ln a$ for all $a>0$ and $H: N(X)^{2} \rightarrow[0,+\infty]$ is the Hausdorff metric on $N(X)$, then $F$ satisfies (F1)-(F3) and each mapping $G: X \longrightarrow C B(X)$ is an $F$-contraction such that $H(G x, G y) \leqslant e^{-\tau} d(x, y)$ for all $x, y \in X$.

Definition 2.2. Ordered-close operator is set-valued operator $G: X \rightarrow C B(X)$ if for two monotone sequences $\left\{x_{n}\right\},\left\{y_{n}\right\} \subset X$ and $x_{0}, y_{0} \in X ; x_{n} \rightarrow x_{0}, y_{n} \rightarrow y_{0}$ and $y_{n} \in G\left(x_{n}\right)$ imply $y_{0} \in G\left(x_{0}\right)$.

Theorem 2.1. Let $(X, d, \preceq)$ be a sequentially complete metric space. Also, let the mapping $G: X \longrightarrow C B(X)$ be an ordered-close set-valued F-contraction and has UCAV. Then G has a fixed point $x^{*} \in X$.

Proof. Let $x_{0} \in X$. If $x_{0} \in G x_{0}$, then our proof is complete. Otherwise, since $G$ has UCAV, there exists $x_{1} \in G x_{0}$ with $x_{0} \neq x_{1}$ and $x_{0} \preceq x_{1}$ such that $d\left(x_{0}, x_{1}\right)=\inf _{x \in G x_{0}} d\left(x_{0}, x\right)=D\left(x_{0}, G x_{0}\right)$. Continue this procedure, we obtain a non-decreasing sequence $\left\{x_{n}\right\}$, where $x_{n} \in G x_{n-1}$ with $x_{n-1} \preceq x_{n}$ and $x_{n-1} \neq x_{n}$ such that $d\left(x_{n}, x_{n+1}\right)=\inf _{x \in G x_{n}} d\left(x_{n}, x\right)=D\left(x_{n}, G x_{n}\right)$. On the other hand,

$$
D\left(x_{n}, G x_{n}\right) \leqslant \sup _{x \in G x_{n-1}} D\left(x, G x_{n}\right) \leqslant H\left(G x_{n}, G x_{n-1}\right) .
$$


Therefore, $d\left(x_{n}, x_{n+1}\right) \leqslant H\left(G x_{n}, G x_{n-1}\right)$. From $(\mathrm{F} 1)$, we have $F\left(d\left(x_{n}, x_{n+1}\right)\right) \leqslant$ $F\left(H\left(G x_{n}, G x_{n-1}\right)\right)$. In addition, $G$ is $F$-contraction. Thus,

$$
\begin{aligned}
F\left(d\left(x_{n}, x_{n+1}\right)\right) \leqslant F\left(H\left(G x_{n}, G x_{n-1}\right)\right) \\
\leqslant F\left(d\left(x_{n}, x_{n-1}\right)\right)-\tau \\
\leqslant F\left(d\left(x_{n-2}, x_{n-1}\right)\right)-2 \tau \\
\leqslant \\
\\
\vdots \\
\leqslant F\left(d\left(x_{0}, x_{1}\right)\right)-n \tau .
\end{aligned}
$$

We obtain $\lim _{n \rightarrow \infty} F\left(d\left(x_{n}, x_{n+1}\right)\right)=-\infty$ that together with (F2) gives

$$
\lim _{n \rightarrow \infty} d\left(x_{n}, x_{n+1}\right)=0
$$

Denote $\gamma_{n}=d\left(x_{n}, x_{n+1}\right)$. By (F3), there exists $k \in(0,1)$ such that

$$
\lim _{n \rightarrow \infty} \gamma_{n}^{k} F\left(\gamma_{n}\right)=0
$$

By (2), we have

$$
\gamma_{n}^{k} F\left(\gamma_{n}\right)-\gamma_{n}^{k} F\left(\gamma_{0}\right) \leqslant \gamma_{n}^{k}\left(F\left(\gamma_{0}\right)-n \tau\right)-\gamma_{n}^{k} F\left(\gamma_{0}\right)=-\gamma_{n}^{k} n \tau \leqslant 0
$$

for all $n \in \mathbb{N}$. Letting $n \rightarrow \infty$ in (5), and applying (3) and (4), we obtain $\lim _{n \rightarrow \infty} n \gamma_{n}^{k}=0$. Hence, there exists $n_{1} \in \mathbb{N}$ such that $n \gamma_{n}^{k} \leqslant 1$ for each $n \geqslant n_{1}$. Consequently, we have

$$
\gamma_{n} \leqslant \frac{1}{\sqrt[k]{n}}<1
$$

for all $n \geqslant n_{1}$. In order to show that $\left\{x_{n}\right\}$ is a Cauchy sequence, let $m, n \in \mathbb{N}$ with $m>n \geqslant n_{1}$. From the definition of the metric and (6), we obtain

$$
d\left(x_{n}, x_{m}\right) \leqslant \gamma_{m-1}+\gamma_{m-2}+\cdots+\gamma_{n}<\sum_{i=n}^{\infty} \gamma_{i} \leqslant \sum_{i=n}^{\infty} \frac{1}{\sqrt[k]{i}}
$$

From (7) and the convergence of the series $\sum_{i=n}^{\infty} \frac{1}{\sqrt[k]{i}}$, we conclude that $\left\{x_{n}\right\}$ is Cauchy sequence. From the completeness of $X$, there exists $x^{*} \in X$ such that $\lim _{n \rightarrow \infty} x_{n} \rightarrow x^{*}$. Since $G$ is orderedclose operator, $\left\{x_{n}\right\}$ is monotone and $x_{n+1} \in G\left(x_{n}\right)$, we deduce $x^{*} \in G\left(x^{*}\right)$ and $x^{*}$ is a fixed point of $G$.

Theorem 2.2. Let $(X, d, \preceq)$ be a sequentially complete metric space. Also, let the mapping $G: X \rightarrow C B(X)$ be an ordered-close set-valued F-contraction and has LCAV. Then $G$ has a fixed point $x^{*} \in X$.

Proof. The proof is similar to Theorem 2.1 .

Example 2.3. Consider the sequence $\left\{S_{n}\right\}_{n \in \mathbb{N}}$ by $S_{1}=1$ and $S_{n}=1+2+\cdots+n=\frac{n(n+1)}{2}$ for all $n \in \mathbb{N}$. Let $X=\left\{S_{n}: n \in \mathbb{N}\right\}$ and $d(x, y)=|x-y|$ for all $x, y \in X$. Also, we define the relation " $\preceq$ " on $X$ by $x \preceq y \Leftrightarrow S_{p} \leqslant S_{q}$ for all $x=S_{p}, y=S_{q} \in X$. Then $(X, d, \preceq)$ is a sequentially complete metric space. Also, let the mapping $G: X \rightarrow C B(X)$ be a ordered-close 
set-valued mapping and has LCAV defined by $G\left(S_{1}\right)=\left\{S_{1}\right\}$ and $G\left(S_{n}\right)=\left[1, S_{n-1}\right]$ for all $n>1$. Then $G$ is an $F$-contraction with $F$ as in Example 2.1 and $\tau=1$. To see this, let us consider the following calculations:

For each $m, n \in \mathbb{N}$ with $m>2$ and $n=1$, we have

$$
H\left(G\left(S_{m}\right), G\left(S_{1}\right)\right)=\max \left\{\sup _{a \in G\left(S_{m}\right)} D\left(a, G\left(S_{1}\right)\right), \sup _{b \in G\left(S_{1}\right)} D\left(b, G\left(S_{m}\right)\right)\right\}=d\left(S_{m-1}, S_{1}\right)
$$

and

$$
\begin{aligned}
\frac{H\left(G\left(S_{m}\right), G\left(S_{1}\right)\right)}{d\left(S_{m}, S_{1}\right)} e^{H\left(G\left(S_{m}\right), G\left(S_{1}\right)\right)-d\left(S_{m}, S_{1}\right)} & =\frac{d\left(S_{m-1}, S_{1}\right)}{d\left(S_{m}, S_{1}\right)} e^{d\left(S_{m-1}, S_{1}\right)-d\left(S_{m}, S_{1}\right)}= \\
& =\frac{S_{m-1}-1}{S_{m}-1} e^{S_{m-1}-S_{m}}= \\
& =\frac{m^{2}-m-2}{m^{2}+m-2} e^{-m}<e^{-m}<e^{-1} .
\end{aligned}
$$

Now, for each $m, n \in \mathbb{N}$ with $m>n>1$, we have

$$
H\left(G\left(S_{m}\right), G\left(S_{n}\right)\right)=\max \left\{\sup _{a \in G\left(S_{m}\right)} D\left(a, G\left(S_{n}\right)\right), \sup _{b \in G\left(S_{n}\right)} D\left(b, G\left(S_{m}\right)\right)\right\}=d\left(S_{m-1}, S_{n-1}\right)
$$

and

$$
\begin{aligned}
\frac{H\left(G\left(S_{m}\right), G\left(S_{n}\right)\right)}{d\left(S_{m}, S_{n}\right)} e^{H\left(G\left(S_{m}\right), G\left(S_{n}\right)\right)-d\left(S_{m}, S_{n}\right)} & =\frac{d\left(S_{m-1}, S_{n-1}\right)}{d\left(S_{m}, S_{n}\right)} e^{d\left(S_{m-1}, S_{n-1}\right)-d\left(S_{m}, S_{n}\right)}= \\
& =\frac{S_{m-1}-S_{n-1}}{S_{m}-S_{n}} e^{S_{n}-S_{n-1}+S_{m-1}-S_{m}}= \\
& =\frac{m+n-1}{m+n+1} e^{n-m}<e^{n-m}<e^{-1} .
\end{aligned}
$$

Therefore, by Theorem 2.2, $S_{1}$ is a fixed point of $G$.

Theorem 2.3. Let $(X, d, \preceq)$ be a sequentially complete metric space. Suppose that the mapping $G: X \rightarrow C B(X)$ is an ordered-close set-valued $F$-contraction and has $A V$. If there exists $x_{0} \in X$ such that $\left\{x_{0}\right\} \sqsubseteq G x_{0}$, then $G$ has a fixed point $x^{*} \in X$.

Proof. If $x_{0} \in G x_{0}$, then the proof is finished. Otherwise, by Definition 1.2, we have $x \succeq x_{0}$ for any $x \in G x_{0}$. Since $G$ has approximative values, there exists $x_{1} \in G x_{0}$ with $x_{1} \succeq x_{0}$ and $x_{0} \neq x_{1}$ such that $d\left(x_{0}, x_{1}\right)=D\left(x_{0}, G x_{0}\right)$. Continue this procedure, we have a non-decreasing sequence $\left\{x_{n}\right\}$ with $x_{n-1} \preceq x_{n}$, where $x_{n} \in G x_{n-1}$ and $x_{n} \neq x_{n-1}$ such that $d\left(x_{n}, x_{n+1}\right)=$ $=\inf _{x \in G x_{n}} d\left(x_{n}, x\right)=D\left(x_{n}, G x_{n}\right)$. The rest of this proof is the same as that of Theorem 2.1.

Theorem 2.4. Let $(X, d, \preceq)$ be a sequentially complete metric space. Suppose that the mapping $G: X \rightarrow C B(X)$ be an ordered-close set-valued $F$-contraction and has $A V$. If there exists $x_{0} \in X$ such that $G x_{0} \sqsubseteq\left\{x_{0}\right\}$, then $G$ has a fixed point $x^{*} \in X$.

Proof. The proof is similar to Theorem 2.2.

Theorem 2.5. Let $(X, d, \preceq)$ be a sequentially complete metric space. Also, let the mapping $G: X \longrightarrow C B(X)$ be an ordered-close set-valued and has UCAV. If we have

$$
F(H(G x, G y)) \leqslant F(M(x, y))-\tau
$$


for all $x, y \in X$, where

$$
M(x, y)=\max \left\{d(x, y), D(x, G x), D(y, G y), \frac{1}{2}[D(x, G y)+D(y, G x)]\right\},
$$

then $G$ has a fixed point $x^{*} \in X$.

Proof. Let $x_{0} \in X$. If $x_{0} \in G x_{0}$, then the proof is complete. Otherwise, Since $G$ has UCAV, there exists $x_{1} \in G x_{0}$ with $x_{0} \neq x_{1}$ and $x_{0} \preceq x_{1}$ such that $d\left(x_{0}, x_{1}\right)=\inf _{x \in G x_{0}} d\left(x_{0}, x\right)=D\left(x_{0}, G x_{0}\right)$.

Continue this procedure, we obtain a non-decreasing sequence $\left\{x_{n}\right\}$ with $x_{n-1} \preceq x_{n}$, where $x_{n} \in G x_{n-1}$ and $x_{n} \neq x_{n-1}$ such that $d\left(x_{n}, x_{n+1}\right)=\inf _{x \in G x_{n}} d\left(x_{n}, x\right)=D\left(x_{n}, G x_{n}\right)$. On the other hand,

$$
D\left(x_{n}, G x_{n}\right) \leqslant \sup _{x \in G x_{n-1}} D\left(x, G x_{n}\right) \leqslant H\left(G x_{n}, G x_{n-1}\right) .
$$

Therefore, $d\left(x_{n}, x_{n+1}\right) \leqslant H\left(G x_{n}, G x_{n-1}\right)$. Now, from (F1) and (8) we have

$$
F\left(d\left(x_{n}, x_{n+1}\right)\right) \leqslant F\left(H\left(G x_{n}, G x_{n-1}\right)\right) \leqslant F\left(M\left(x_{n}, x_{n-1}\right)\right)-\tau
$$

for all $n \in \mathbb{N}$, where

$$
\begin{aligned}
& M\left(x_{n}, x_{n-1}\right)= \\
& \quad=\max \left\{d\left(x_{n}, x_{n-1}\right), D\left(x_{n}, G x_{n}\right), D\left(x_{n-1}, G x_{n-1}\right), \frac{1}{2}\left[D\left(x_{n}, G x_{n-1}\right)+D\left(x_{n-1}, G x_{n}\right)\right]\right\} .
\end{aligned}
$$

Once more, note that $x_{n+1} \in G x_{n}$ and $D\left(x_{n}, G x_{n}\right)=d\left(x_{n}, x_{n+1}\right)$. Hence, we have

$$
\begin{aligned}
M\left(x_{n}, x_{n-1}\right) & \leqslant \max \left\{d\left(x_{n}, x_{n-1}\right), d\left(x_{n}, x_{n+1}\right), d\left(x_{n-1}, x_{n}\right), \frac{1}{2}\left[d\left(x_{n}, x_{n}\right)+d\left(x_{n-1}, x_{n+1}\right)\right]\right\} \leqslant \\
& \leqslant \max \left\{d\left(x_{n}, x_{n-1}\right), d\left(x_{n}, x_{n+1}\right), \frac{1}{2}\left[d\left(x_{n-1}, x_{n}\right)+d\left(x_{n}, x_{n+1}\right)\right]\right\} \leqslant \\
& \leqslant \max \left\{d\left(x_{n}, x_{n-1}\right), d\left(x_{n}, x_{n+1}\right)\right\} .
\end{aligned}
$$

If $\max \left\{d\left(x_{n}, x_{n-1}\right), d\left(x_{n}, x_{n+1}\right)\right\}=d\left(x_{n}, x_{n+1}\right)$, then $F\left(d\left(x_{n}, x_{n+1}\right)\right) \leqslant F\left(d\left(x_{n}, x_{n+1}\right)\right)-\tau$, which contradicts with $\tau>0$. Thus, we have $F\left(d\left(x_{n}, x_{n+1}\right)\right) \leqslant F\left(d\left(x_{n}, x_{n-1}\right)\right)-\tau$. The rest of the proof is in the similar manner given in Theorem 2.1.

Theorem 2.6. Let $(X, d, \preceq)$ be a sequentially complete metric space. Assume that the mapping $G: X \longrightarrow C B(X)$ is an ordered-close set-valued and has $L C A V$, and $F(H(G x, G y)) \leqslant$ $F(M(x, y))-\tau$ for all $x, y \in X$, where

$$
M(x, y)=\max \left\{d(x, y), D(x, G x), D(y, G y), \frac{1}{2}[D(x, G y)+D(y, G x)]\right\} .
$$

Then $G$ has a fixed point $x^{*} \in X$.

Proof. Let $x_{0} \in X$. If $x_{0} \in G x_{0}$, then the proof is complete. Otherwise, Since $G$ has LCAV, there exists $x_{1} \in G x_{0}$ with $x_{0} \neq x_{1}$ and $x_{1} \preceq x_{0}$ such that $d\left(x_{0}, x_{1}\right)=\inf _{x \in G x_{0}} d\left(x_{0}, x\right)=D\left(x_{0}, G x_{0}\right)$. Continue this procedure, we obtain a non-increasing sequence $\left\{x_{n}\right\}$ with $x_{n} \preceq x_{n-1}$, where $x_{n} \in G x_{n-1}$ and $x_{n} \neq x_{n-1}$ such that $d\left(x_{n}, x_{n+1}\right)=\inf _{x \in G x_{n}} d\left(x_{n}, x\right)=D\left(x_{n}, G x_{n}\right)$. The rest of this proof is the same as that of Theorem 2.5. 
Theorem 2.7. Let $(X, d, \preceq)$ be a sequentially complete metric space. Assume that the mapping $G: X \rightarrow C B(X)$ is an ordered-close set-valued and has $A V$, and $F(H(G x, G y)) \leqslant F(M(x, y))-\tau$ for all $x, y \in X$, where

$$
M(x, y)=\max \left\{d(x, y), D(x, G x), D(y, G y), \frac{1}{2}[D(x, G y)+D(y, G x)]\right\} .
$$

If there exists $x_{0} \in X$ such that $\left\{x_{0}\right\} \sqsubseteq G x_{0}$, then $G$ has a fixed point $x^{*} \in X$.

Proof. If $x_{0} \in G x_{0}$, then the proof is finished. Otherwise, by Definition 1.2, we have $x \succeq x_{0}$ for any $x \in G x_{0}$. Since $G$ has approximative values, there exists $x_{1} \in G x_{0}$ with $x_{1} \succeq x_{0}$ and $x_{0} \neq x_{1}$ such that $d\left(x_{0}, x_{1}\right)=D\left(x_{0}, G x_{0}\right)$. Continue this procedure, we have a non-decreasing sequence $\left\{x_{n}\right\}$ with $x_{n-1} \preceq x_{n}$, where $x_{n} \in G x_{n-1}$ and $x_{n} \neq x_{n-1}$ such that $d\left(x_{n}, x_{n+1}\right)=$ $=\inf _{x \in G x_{n}} d\left(x_{n}, x\right)=D\left(x_{n}, G x_{n}\right)$. The rest of this proof is the same as that of Theorem 2.5.

Theorem 2.8. Let $(X, d, \preceq)$ be a sequentially complete metric space. Assume that the mapping $G: X \rightarrow C B(X)$ is an ordered-close set-valued and has $A V$, and $F(H(G x, G y)) \leqslant F(M(x, y))-\tau$ for all $x, y \in X$, where

$$
M(x, y)=\max \left\{d(x, y), D(x, G x), D(y, G y), \frac{1}{2}[D(x, G y)+D(y, G x)]\right\} .
$$

If there exists $x_{0} \in X$ such that $G x_{0} \sqsubseteq\left\{x_{0}\right\}$, then $G$ has a fixed point $x^{*} \in X$.

Proof. If $x_{0} \in G x_{0}$, then the proof is finished. Otherwise, by Definition 1.2, we have $x_{0} \succeq x$ for any $x \in G x_{0}$. Since $G$ has approximative values, there exists $x_{1} \in G x_{0}$ with $x_{0} \succeq x_{1}$ and $x_{0} \neq x_{1}$ such that $d\left(x_{0}, x_{1}\right)=D\left(x_{0}, G x_{0}\right)$. Continue this procedure, we have a non-increasing sequence $\left\{x_{n}\right\}$ with $x_{n} \preceq x_{n-1}$, where $x_{n} \in G x_{n-1}$ and $x_{n} \neq x_{n-1}$ such that $d\left(x_{n}, x_{n+1}\right)=$ $=\inf _{x \in G x_{n}} d\left(x_{n}, x\right)=D\left(x_{n}, G x_{n}\right)$. The rest of this proof is the same as that of Theorem 2.5.

\section{Application to integral equation}

As an application of our results, we will consider the following Volterra integral equation:

$$
x(t)=\int_{0}^{t} K(t, s, x(s)) d s+g(t),
$$

where $I=[0,1], K \in C(I \times I \times \mathbb{R}, \mathbb{R})$ and $g \in C(I, \mathbb{R})$ for all $t \in I$.

Let $C(I, \mathbb{R})$ be the Banach space of all real continuous functions defined on $I$ with the sup norm $\|x\|_{\infty}=\max _{t \in I}|x(t)|$ for all $x \in C(I, \mathbb{R})$ and $C(I \times I \times C(I, \mathbb{R}), \mathbb{R})$ be the space of all continuous functions defined on $I \times I \times C(I, \mathbb{R})$. Alternatively, the Banach space $C(I, \mathbb{R})$ can be endowed with Bielecki norm $\|x\|_{B}=\sup _{t \in I}\left\{|x(t)| e^{-\tau t}\right\}$ for all $x \in C(I, \mathbb{R})$ and $\tau>0$, and the induced metric $d_{B}(x, y)=\|x-y\|_{B}$ for all $x, y \in C(I, \mathbb{R})$ (see $\left.[5]\right)$. Also, let $f: C(I, \mathbb{R}) \rightarrow C(I, \mathbb{R})$

defined by $f x(t)=\int_{0}^{t} K(t, s, x(s)) d s+g(t)$ and $g \in C(I, \mathbb{R})$. Moreover, we define the relation " $\preceq$ " on $C(I, \mathbb{R})$ by $x \preceq y \Leftrightarrow\|x\|_{\infty} \leqslant\|y\|_{\infty}$ for all $x, y \in C(I, \mathbb{R})$. Clearly the relation " $\preceq$ " is a quasi-order relation.

Theorem 3.1. Let $\left(C(I, \mathbb{R}), d_{B}, \preceq\right)$ be a sequentially complete metric space. Suppose that $G$ : $C(I, \mathbb{R}) \rightarrow C B(C(I, \mathbb{R}))$ is a set-valued operator such that $G(x)=\{f x(t)\}$ and has UCAV. Let $K \in C(I \times I \times \mathbb{R}, \mathbb{R})$ be an operator satisfying the following conditions: 
(i) $K$ is continuous;

(ii) $\int_{0}^{t} K(t, s,$.$) for all t, s \in I$ is increasing;

(iii) there exists $\tau>0$ such that $|K(t, s, x(s))-K(t, s, y(s))| \leqslant e^{-\tau}|x(s)-y(s)|$ for all $x, y \in$ $C(I, \mathbb{R})$ and all $t, s \in I$.

Then, the Volterra-type integral equation (9) has a solution in $C(I, \mathbb{R})$.

Proof. By definition of $G$, we have $H(G x, G y)=d_{B}(f(x), f(y))$ for all $x, y \in C(I, \mathbb{R})$. Thus,

$$
\begin{aligned}
H(G x, G y)=d_{B}(f(x), f(y)) & =\sup _{t \in I}\left\{\left|\int_{0}^{t} K(t, s, x(s)) d s-\int_{0}^{t} K(t, s, y(s)) d s\right| e^{-\tau t}\right\} \\
& \leqslant \sup _{t \in I}\left\{\int_{0}^{t}|K(t, s, x(s))-K(t, s, y(s))| e^{-\tau t} d s\right\} \\
& \leqslant \sup _{t \in I}\left\{\int_{0}^{t} e^{-\tau}|x(s)-y(s)| e^{-\tau t} d s\right\} \\
& \leqslant\|x-y\|_{B} \sup _{t \in I}\left\{\int_{0}^{t} e^{-\tau} d s\right\} \\
& =e^{-\tau} d_{B}(x, y) .
\end{aligned}
$$

Taking logarithms, we have $\ln (H(G x, G y)) \leqslant \ln \left(e^{-\tau} d_{B}(x, y)\right)$, which implies that $(\tau+$ $+\ln (H(G x, G y))) \leqslant \ln \left(d_{B}(x, y)\right)$. Now, consider the function $F(t)=\ln (t)$ for all $t \in C(I, \mathbb{R})$ and $\tau>0$. Then, all conditions of Theorem 2.1 are satisfied. Consequently, Theorem 2.1 ensures the existence of fixed point of $G$ that this fixed point is the solution of the integral equation.

We are grateful to the Research Council of Shahid Chamran University of Ahvaz for financial support (Grant number: SCU.MM99.25894).

\section{References}

[1] R.P.Agarwal, M.A.El-Gebeily, D.O'Regan, Generalized contractions in partially ordered metric spaces, Appl. Anal., 87(2008), 1-8.

[2] A.Amini-Harandi, Fixed point theory for set-valued quasi-contraction maps in metric spaces, Appl. Math. Lett., 24(2011), 1791-1794. DOI: 10.1016/j.aml.2011.04.033

[3] S.Banach, Surles operations dans les ensembles abstraits et leurs application auxequations integrales, Fund. Math., 3(1922), 133-181.

[4] T.G.Bhaskar, V.Lakshmikantham, Fixed point theorems in partially ordered metric spaces and applications, Nonlinear Anal., 65(2006), 1379-1393.

[5] A.Bielecki, Une remarque sur la methode de Banach-Cacciopoli-Tikhonov dans la theorie des equations differentielles ordinaires, Bull. Acad. Polon. Sci. Ser. Sci. Math. Astronom. Phys., 4(1956), 261-264.

[6] Lj.Ćirić, Fixed points for generalized multi-valued contractions, Math. Ves., 24(1972), $265-272$. 
[7] E.L.Ghasab, H.Majani, E.Karapinar, G.Soleimani Rad, New fixed point results in F-quasimetric spaces and an application, Adv. Math. Phys., 2020, 2020:9452350.

DOI: $10.1155 / 2020 / 9452350$

[8] Z.Kadelburg, S.Radenović, Notes on some recent papers concerning $F$-contractions in $b$ metric spaces, Construct. Math. Anal., 1(2018), 108-112.

[9] H.P.Masiha, F.Sabetghadam, Fixed point results for multi-valued operators in quasi-ordered metric spaces, Appl. Math. Lett., 25(2012), 1856-1861.

[10] S.B.Nadler, Multi-valued contraction mappings, Pacific J. Math., 30(1969), 475-488.

[11] J.J.Nieto, R.Rodriguez-Lopez, Contractive mapping theorems in partially ordered sets and applications to ordinary differential equations, Order., 22(2005), 223-239.

[12] A.C.M.Ran, M.C.B.Reurings, A fixed point theorem in partially ordered sets and some applications to matrix equations, Proc. Amer. Math. Soc., 132(2004), 1435-1443.

[13] R.Saadati, S.M.Vaezpour, Monotone generalized weak contractions in partially ordered metric spaces, Fixed Point Theory., 11(2010), 375-382.

[14] D.Wardowski, Fixed points of a new type of contractive mappings in complete metric spaces, Fixed Point Theory Appl., 2012, 2012:94.

[15] D.Wardowski, Solving existence problems via F-contractions, Proc. Amer. Math. Soc., 146(2018), 1585-1598.

\title{
Неподвижные точки многозначных операторов $F$-сжатия в квазиупорядоченных метрических пространствах с приложением к интегральным уравнениям
}

\author{
Эхсан Л. Гасаб \\ Хамид Маджани \\ Университет Шахида Чамрана в Ахвазе \\ Ахваз, Иран \\ Гасем С. Рад \\ Исламский университет Азад \\ Тегеран, Иран
}

\begin{abstract}
Аннотация. В этой статье мы докажем некоторые новые теоремы о неподвижных точках, включающие многозначные $F$-сжатия в условиях квазиупорядоченных метрических пространств. Наши результаты важны, поскольку мы представляем принцип банахового сжатия иначе, чем тот, который известен в настоящей литературе. Для подтверждения полученных результатов приведены некоторые примеры и приложение к существованию решения интегрального уравнения типа Вольтерра.

Ключевые слова: неподвижная точка, $F$-сжатие, секвенциально полные метрические пространства, оператор упорядоченного замыкания.
\end{abstract}

